\title{
Expansão rápida da maxila ancorada em implantes - uma nova proposta para expansão ortopédica na dentadura permanente
}

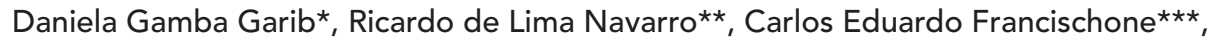

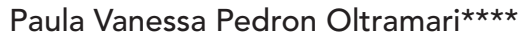

\begin{abstract}
Resumo
Objetivo: este trabalho apresenta um método para expansão ortopédica da maxila, na dentadura permanente, utilizando implantes como ancoragem. Metodologia: detalharam-se os procedimentos cirúrgicos e laboratoriais da confecção de um expansor com ancoragem dentoóssea em crânio seco humano. Dois implantes de titânio foram colocados na região anterior do palato, e o parafuso Hyrax adaptado de modo que a expansão ancorou-se nos implantes e nos primeiros molares permanentes. Resultados: o experimento laboratorial em crânio seco mostrou que o procedimento apresenta-se anatômica e operacionalmente viável. Os implantes suportaram a força gerada pela ativação do parafuso expansor, redundando na separação transversal das hemimaxilas. Conclusões: vislumbra-se que a expansão rápida da maxila ancorada em implantes (ERMAI) poderá potencializar a eficiência da expansão ortopédica, assim como reduzir o custo periodontal dos procedimentos convencionais de expansão. Futuros estudos clínicos são necessários para testar essas hipóteses.
\end{abstract}

Palavras-chave: Ortodontia. Ortopedia. Expansão rápida da maxila. Implantes. Dentadura permanente.

\section{INTRODUÇÃO}

Ao se executar o procedimento de expansão rápida da maxila (ERM), com finalidade de corrigir a atresia do arco dentário superior, o principal efeito almejado pelo ortodontista consiste na abertura da sutura intermaxilar e conseqüente incremento transversal da base óssea superior. Porém, concomitantemente a este desejável efeito ortopédico, a ERM inevitavelmente redunda em um efeito ortodôntico de movimentação dentária vestibular, uma vez que os expansores ancoram-se diretamente sobre os dentes superiores $5,6,12,15,27,28$. Portanto, parte da abertura do parafuso expansor, visando o aumento em largura da maxila, dissipase com a movimentação dos dentes de ancoragem para vestibular. Estima-se que o efeito ortodôntico corresponda, em média, a 50\% da quantidade de abertura do parafuso expansor, durante as fases de dentadura decídua e mista, e cerca de $2 / 3$ da quantidade de expansão, durante a dentadura

\footnotetext{
* Professora Associada de Ortodontia da Universidade Cidade de São Paulo - UNICID - São Paulo. Professora do Curso de Ortodontia Preventiva e Interceptora da PROFIS - Bauru. Coordenadora do curso de especialização em Ortodontia da Prevodonto - Centro de Estudos - Rio de Janeiro.

* Mestre em Patologia Bucal pela Faculdade de Odontologia, Universidade de São Paulo. Doutorando em Ortodontia pela Faculdade de Odontologia de Bauru, Universidade de São Paulo. Especialista em Cirurgia e Traumatologia Bucomaxilofacial pela Universidade Sagrado Coração.

*** Professor Titular do Departamento de Dentística da Faculdade de Odontologia de Bauru, Universidade de São Paulo. Professor Titular de Implantologia e Dentística da Universidade do Sagrado Coração.

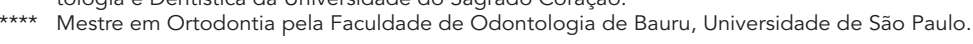


permanente ${ }^{15}$. Isto corresponde a dizer que, com o aumento da idade e com o aumento da resistência óssea e sutural, espera-se um maior efeito dentário, em detrimento da separação intermaxilar ${ }^{2}$.

A ERM traduz-se em um procedimento rotineiramente utilizado na Ortodontia Corretiva, previamente à mecanoterapia com aparelhos fixos. Minimizar o efeito ortodôntico da expansão na fase de dentadura permanente significaria potencializar o efeito ortopédico, o ganho no perímetro do arco dentário, a estabilidade da expansão e a preservação da anatomia e saúde periodontais em longo prazo. Com este intento, apresentamos a proposta de utilizar implantes de titânio como ancoragem absoluta para a execução da expansão ortopédica da maxila.

Após a descoberta da osseointegração e introdução dos implantes de titânio como solução protética na Odontologia, por Branenmark ${ }^{3}$, vários autores $^{8,14,18,22,25}$ passaram a utilizar os implantes osseointegráveis como dispositivos de ancoragem para a movimentação ortodôntica. Os bons resultados, constatados em estudos experimentais aplicando-se forças ortodônticas e suaves sobre os implantes, encorajaram a sua utilização também para propósitos ortopédicos. Assim, os implantes foram utilizados com a finalidade de ancoragem para Ortopedia Facial (protração maxilofacial), recebendo forças intensas, e demonstraram boa estabilidade em animais ${ }^{20,23}$. No final da década de 90 , Parr et al. ${ }^{17}$ estudaram a expansão sutural utilizando implantes osseointegrados em coelhos. Estes autores reportaram uma expansão da sutura nasal mediana de 5,2 a $6,8 \mathrm{~mm}$, aplicando-se forças de 100 a 300g em implantes colocados bilateralmente a esta sutura, externamente à face média. Recentemente, em 2004, Harzer et al. ${ }^{13}$ indicaram a expansão rápida da maxila assistida cirurgicamente com ancoragem sobre implantes no palato, com o intento de evitar a inclinação dos dentes pósterosuperiores para vestibular, assim como evitar reabsorção óssea e radicular nestas regiões.
Seguindo o trajeto histórico da ancoragem absoluta em Ortopedia, nenhum estudo prévio propôs ou investigou a expansão ortopédica da maxila utilizando ancoragem sobre implantes, em humanos. Desta maneira, o objetivo deste estudo foi descrever e discutir um inédito sistema para expansão rápida da maxila com ancoragem absoluta, para aplicação na fase de dentadura permanente, em pacientes em crescimento.

\section{MATERIAL E MÉTODOS}

O aparelho desenvolvido para a realização da ERMAI ancora-se posteriormente aos primeiros molares superiores e anteriormente a dois implantes inseridos no palato, entre as raízes do primeiro e do segundo pré-molar, bilateralmente. Utilizando-se o parafuso expansor Hyrax, suas extensões posteriores são soldadas aos primeiros molares, enquanto suas extensões anteriores são adaptadas a um anel intermediário, de modo a permitir sua fixação aos implantes, por meio de um parafuso (Fig. 1).

Idealizaram-se implantes de titânio específicos para a ERMAI (implantes experimentais), com desenho adequado e as menores dimensões possíveis, para fornecer a estabilidade necessária diante das forças geradas pela ERM (diâmetro de

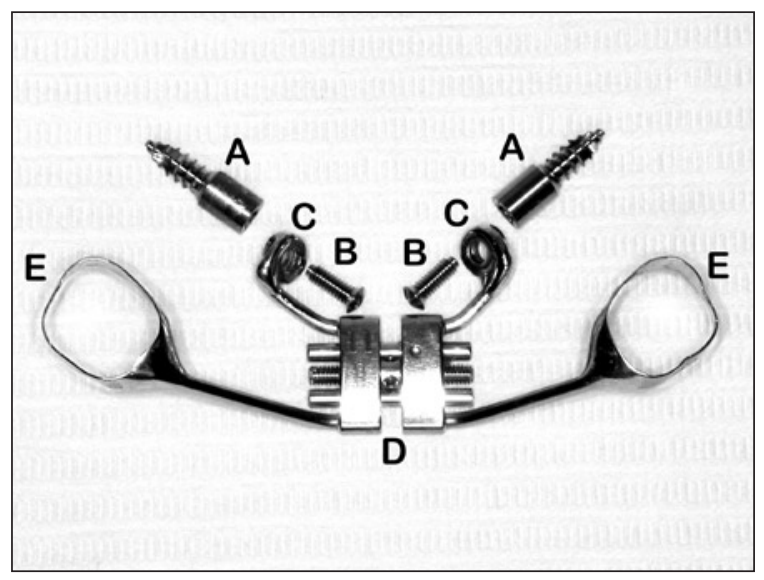

FIGURA 1 - Componentes do aparelho para ERMAl: A) implantes de titânio, B) parafuso para fixação, C) anel intermediário de aço, D) expansor tipo Hyrax e E) bandas. 

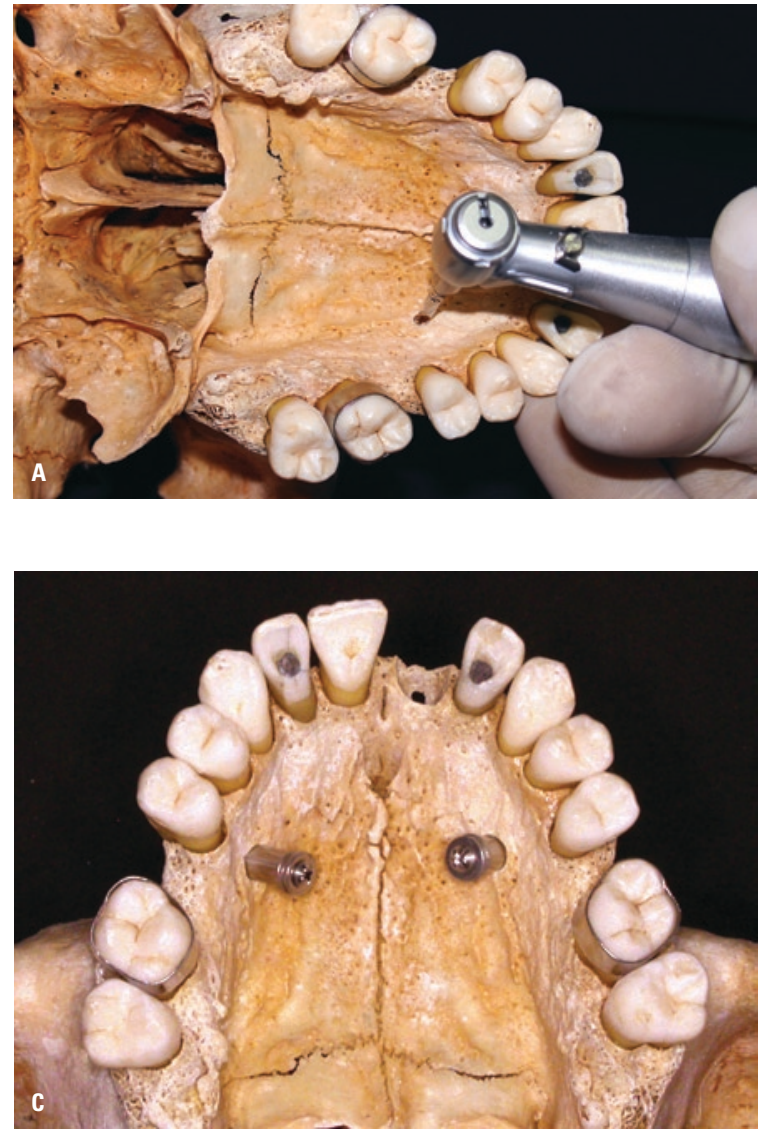

FIGURA 2 - Procedimento cirúrgico para a instalação dos implantes para a ERMAI.

$3 \mathrm{~mm}$ e comprimento variando entre 7 e $15 \mathrm{~mm}$, sendo composto de uma porção intermediária, transmucosa, e outra com rosca). Esta proposta foi estudada e desenvolvida em crânio seco humano. A seqüência cirúrgica segue os protocolos estabelecidos na literatura para a instalação de implantes utilizados na reabilitação protética ${ }^{4}$, porém apenas uma fase cirúrgica se faz necessária. Recomenda-se mínima instrumentação possível, pois a maxila freqüentemente não se apresenta com alta densidade óssea. Assim, o cirurgião deve apenas favorecer a correta direção para que o implante seja adequadamente instalado (Fig. 2).

Há que se ressaltar, ainda, a importância da mensuração da espessura da mucosa do palato, para que seja utilizado um implante com área transmucosa adequada. Desta forma, o implante
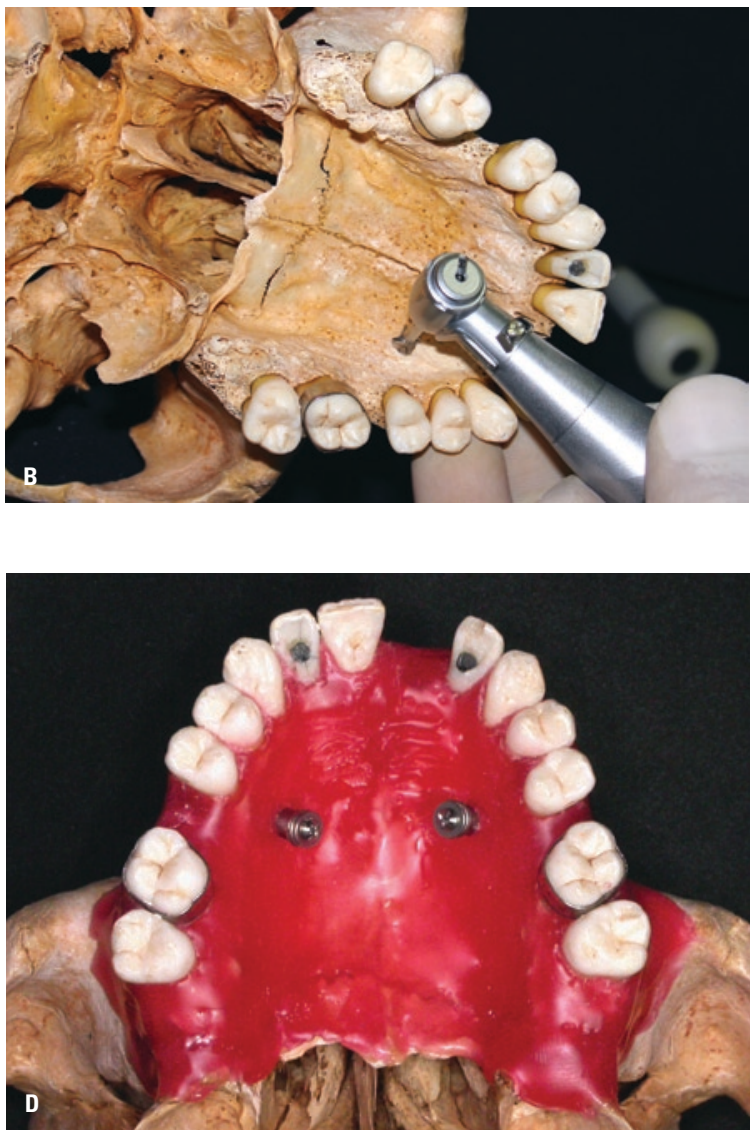

utilizado possui algumas opções de comprimento relativo à área transmucosa. Com relação ao tamanho final do implante instalado, o comprimento extramucoso deve ser de aproximadamente 1 a $2 \mathrm{~mm}$, para permitir a moldagem de transferência e um conforto maior para o paciente após a instalação do aparelho.

Para a escolha da área que possibilite a maior eficiência durante o procedimento de ERM e o menor risco ao paciente, devem ser consideradas as estruturas anatômicas da área em questão. Métodos radiográficos devem permitir que todas estas estruturas possam ser corretamente examinadas e a melhor posição, angulação e profundidade do implante sejam definidas. Para tanto, os exames recomendados são as radiografias: panorâmica, oclusal total de maxila e periapicais, quando necessárias. 
Ainda nesse sentido, alguns detalhes precisam ser criteriosamente avaliados na fase précirúrgica:

- Os limites do seio maxilar devem ser identificados e bem estudados durante o planejamento, identificando possíveis pneumatizações;

- O posicionamento radicular pode dificultar a escolha da melhor posição do implante, nos casos em que exista acentuada convergência entre as raízes, sendo necessária, em alguns casos, Ortodontia prévia para aumentar a divergência entre as raízes e assim permitir a colocação dos implantes;

- A densidade óssea da maxila pode ser um fator de risco quando não houver planejamento adequado, mas com o domínio da técnica devese potencializar o travamento do implante em regiões mais densas, para posterior carga durante a expansão;

- O palato deficiente no sentido transversal é normalmente atrésico e profundo e, conseqüentemente, com as paredes mediais dos processos alveolares mais próximas do paralelismo do que em pacientes normais, e com relações diferentes de paciente para paciente entre a parede lateral da fossa nasal e o encontro entre os processos alveolares e processos palatinos.

A área de escolha para instalação dos implantes é a região do encontro entre os processos alveolares e os processos palatinos, entre as raízes dos primeiros e segundos pré-molares de cada lado. A direção a ser assumida deve levar em consideração a posição relativa da maxila em função da fossa nasal, tendo como referência a linha média em radiografia oclusal, além da posição das raízes dos primeiros e segundos pré-molares.

Logo após a fase cirúrgica, com a colocação dos implantes, as bandas devem ser adaptadas aos primeiros molares e a moldagem de transferência executada para a confecção do aparelho expansor. As bandas são transferidas e os análogos aos implantes posicionados no molde (Fig. 3). Após vazar o gesso, obtêm-se modelos com a reprodução fiel dos implantes instalados no palato. Um anel intermediário de aço, onde a extensão anterior do parafuso expansor será soldada, é fixado aos análogos, por meio do parafuso. Esta etapa finaliza a confecção do modelo de trabalho (Fig. 4).

Após a confecção laboratorial do aparelho, o expansor é primeiramente cimentado aos primeiros molares. Em seguida, os anéis intermediários estarão localizados sobre os implantes e são fixados a eles, por meio do parafuso (Fig. 5).

\section{DISCUSSÃO}

Ao ancorar o aparelho expansor sobre implantes intra-ósseos inseridos no palato, o efeito esperado durante a ERM consiste na prevenção do efeito dentário representado pela movimentação vestibular dos dentes posteriores. Estudos prévios demonstraram que os dentes que ancoram o aparelho são movimentados para vestibular, com componentes de inclinação e translação associados, durante a ERM convencional $6,12,27,28$. Transferir a ancoragem de elementos passíveis de movimentação, como os dentes, para elementos absolutamente rígidos e imutáveis posicionalmente, como os implantes, redundaria em vantagens incontestáveis.

Desta maneira, toda a força liberada pela abertura do parafuso expansor se reverteria em esforços para promover a separação da sutura intermaxilar. $O$ resultado esperado seria uma maior eficiência da expansão em ocasionar o efeito ortopédico e o aumento transverso da base óssea maxilar (Fig. 6). Adkins et al. ${ }^{1}$, em 1990, demonstraram que a ERM na dentadura permanente ocasiona um aumento no perímetro do arco dentário equivalente a 70\% da quantidade de expansão da largura interprimeiro pré-molares. Poderíamos esperar que, na expansão ortopédica utilizando-se a ancoragem absoluta, o aumento no perímetro do arco dentário seria maximizado. O ganho maior de perímetro ósseo privilegiaria a correção da discrepância negativa dente-osso ou do apinhamento dentário no arco superior, irregularidade freqüentemente 

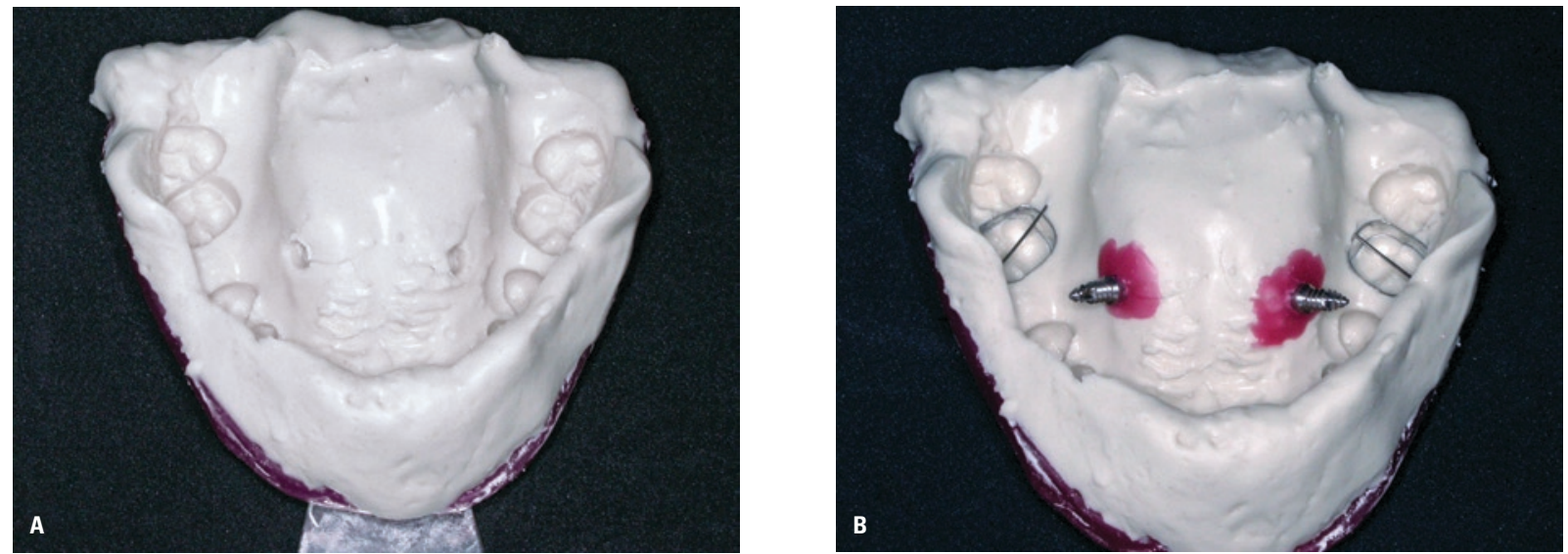

FIGURA 3 - Moldagem de transferência: A) molde obtido, B) com os análogos em posição.

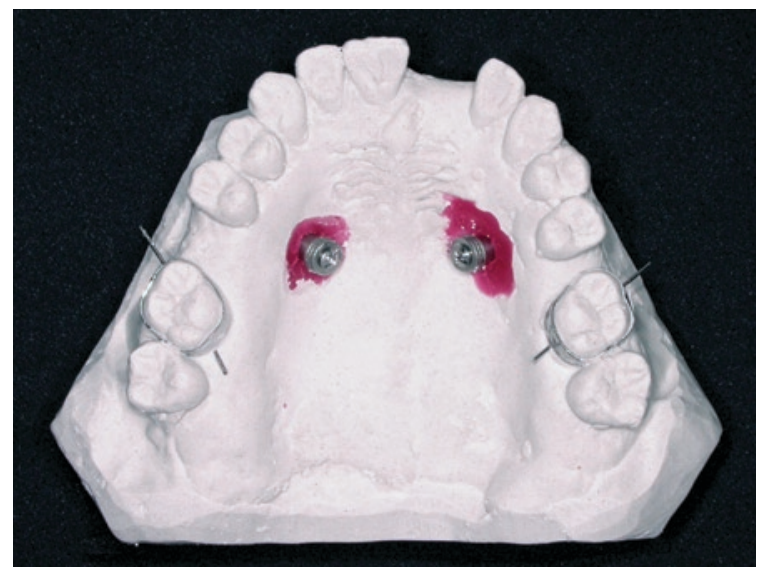

FIGURA 4 - Modelo de trabalho com os análogos em posição.

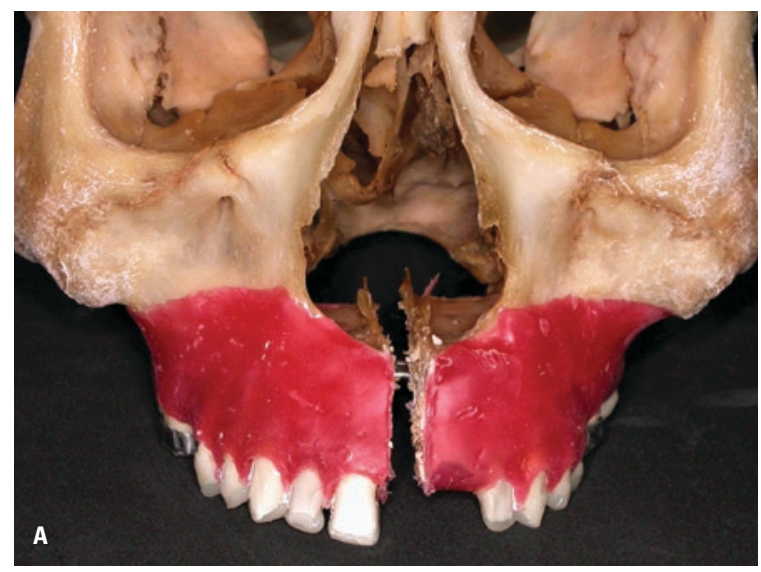

FIGURA 6 - Visão pós-expansão A) frontal e B) oclusal.

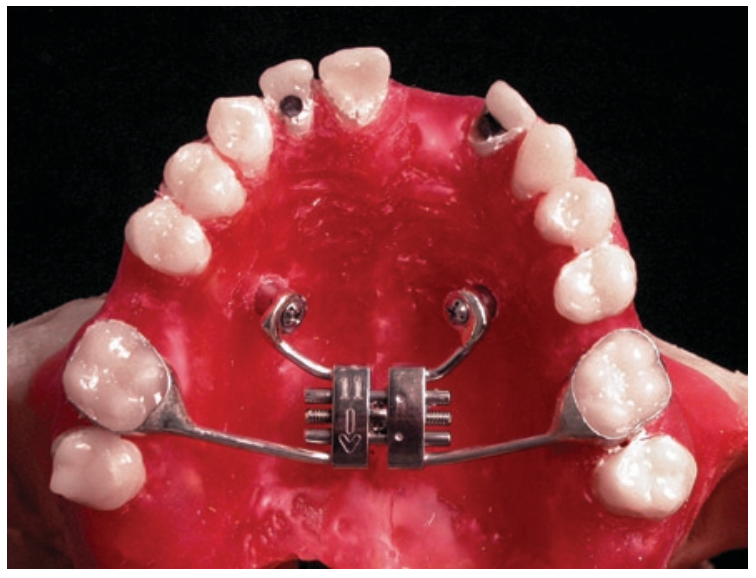

FIGURA 5 - Aparelho para ERMAl instalado. Notar sistemas de ancoragem instalados sobre os molares e implantes.

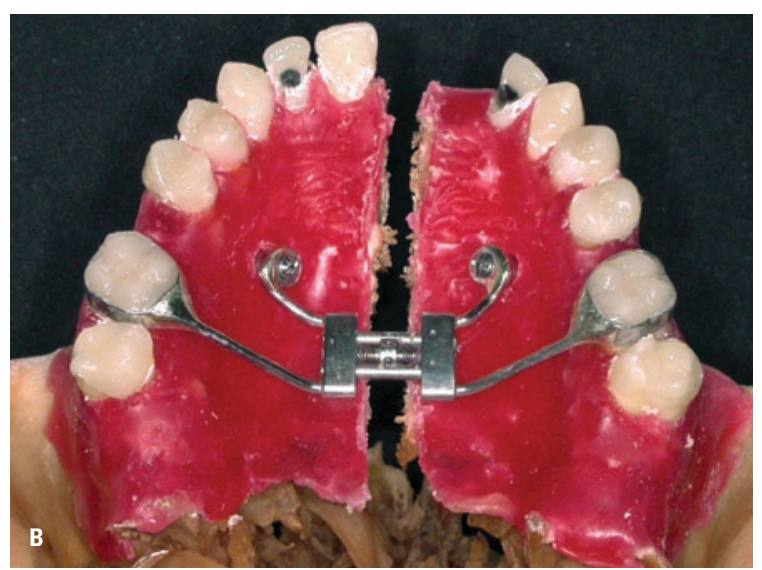


diagnosticada na prática clínica e comumente associada à atresia do arco dentário superior.

Adicionalmente, as vantagens da maior eficiência ortopédica da ERMAI também seriam estendidas para um campo crítico da Ortodontia e da expansão maxilar: a estabilidade longitudinal. Apesar do efeito ortopédico da ERM também poder mostrar algum grau de recidiva ${ }^{15,19}$, trabalhos prévios mostraram que o efeito dentário representa a alteração mais instável após a expansão ${ }^{10,11,21,26}$. Baseado nestes resultados, espera-se que quanto maior o efeito esquelético e menor a movimentação dentária, para uma determinada quantidade de ativação do parafuso, melhor seja o prognóstico em termos de estabilidade.

Estudos anteriores evidenciaram que a ERM ocasiona reabsorção radicular por vestibular dos dentes de ancoragem ${ }^{16}$, reabsorção da tábua óssea vestibular ${ }^{7}$, além do aumento do risco de recessões gengivais em longo prazo $^{9,24}$. Recentemente, Garib et al. ${ }^{7}$, em um estudo com tomografia computadorizada, reportaram que, durante a ERM em jovens na dentadura permanente, os dentes de ancoragem são movimentados através do osso alveolar e não em conjunção com ele. Deste modo, a expansão induziu o desenvolvimento de deiscências ósseas, por vestibular dos dentes de ancoragem, principalmente na região dos primeiros pré-molares e sobretudo em pacientes com tábua óssea vestibular inicialmente delgada. Os resultados ainda atestaram que os expansores dentossuportados (Hyrax) definiram maiores reduções no nível da crista óssea vestibular, comparado aos expansores dentomucossuportados (tipo Haas). À luz do exposto, como evitar estas indesejáveis alterações locais ocasionadas pela expansão? A tentativa de prevenir este perturbador efeito colateral da ERM consistiu no principal motivo que nos impulsionou para o desenvolvimento deste novo e inédito sistema de expansão ortopédica. A ERMAI visa manter os dentes posteriores centralizados no rebordo alveolar, preservando a anatomia periodontal e promovendo a saúde do sistema de sustentação e proteção dos dentes em longo prazo.

Além das diversas vantagens biológicas da expansão com ancoragem absoluta, também se deve destacar uma interessante vantagem operacional. Com o desenho do aparelho incluindo bandas apenas nos primeiros molares superiores, após o período convencional de contenção e neoformação óssea na região da sutura palatina mediana, o nivelamento superior pode ser iniciado sem a necessidade de remoção do expansor. $\mathrm{O}$ próprio aparelho expansor poderia ser mantido como ancoragem prolongada, concomitantemente à mecanoterapia com aparelhos fixos, dispensando o uso das placas removíveis de contenção.

\section{CONCLUSÕES}

Após idealização deste novo sistema de ancoragem, como próximo deverão ser realizados estudos experimentais com a finalidade de atestar sua aplicabilidade clínica. Questões como velocidade da ativação do parafuso, estabilidade dos implantes diante de forças ortopédicas expansoras e o protocolo para adequada inserção dos parafusos devem ainda ser melhor elucidadas.

\section{AGRADECIMENTOS}

Os autores agradecem ao laboratório Laproline-Bauru, pela execução técnica do aparelho expansor. 


\title{
Rapid maxillary expansion anchored by implants - a new proposal to orthope- dic expansion in the permanent dentition
}

\begin{abstract}
Aim: This study presents a method for maxillary orthopedic expansion, in the permanent dentition, using implants as anchorage. Methods: Surgical and laboratorial procedures for the construction of a tooth-bone-borne expansor was detailed in a human dry skull. Two titanium implants were placed in the anterior region of the palate and a Hyrax screw was adapted in a way that the expansion was anchored both on the palatal implants and on permanent first molars. Results: The laboratorial experiment in dry skull showed that the procedure is operationally and anatomically possible. The implants supported the force generated by the expansion screw activation and the maxilla halves were transversally split. Conclusions: Rapid maxillary expansion anchored on implants can increase the efficiency of orthopedic expansion and decrease the periodontal sequela caused by conventional RME. Further clinical studies are necessary to verify these hypotheses.
\end{abstract}

Key words: Orthodontics. Orthopedics. Rapid maxillary expansion. Implants. Permanent dentition.

\section{REFERÊNCIAS}

1. ADKINS, M. D. et al. Arch perimeter changes on rapid palatal expansion. Am. J. Orthod. Dentofacial Orthop., St. Louis, v. 97, no. 3, p. 194-199, Mar. 1990.

2. BACCETTI, T. et al. Treatment timing for maxillary expansion. Angle Orthod., Appleton, v. 71, p. 343-350, 2001.

3. BRANEMARK, P. I. et al. Intra-osseous anchorage of dental prostheses. I. Experimental studies. Scand. J. Plast. Reconstr. Surg., Stockholm, v. 3, no. 2, p. 81-100. 1969.

4. BRANEMARK, P. I. et al. Osseointegration in clinical dentistry. Chicago: Quintessence, 1985.

5. CAPELOZZA FILHO, L.; SILVA FILHO, O. G. Expansão rápida da maxila: considerações gerais e aplicação clínica. Parte II. Rev. Dental Press Ortodon. Ortop. Facial, Maringá, v. 2, n. 4, p. 86108, jul./ago. 1997.

6. GARIB, D. G. et al. Rapid maxillary expansion - tooth-tissue-borne vs. tooth-borne expanders: a computed tomography evaluation of dentoskeletal effects. Angle Orthod., Appleton, v. 75, no. 4, p. 548-557, 2005.

7. GARIB, D. G. et al. Periodontal effects of rapid maxillary expansion with tooth-tissue borne and tooth borne expanders: a computed tomography evaluation. Am. J. Orthod. Dentofacial Orthop., St. Louis, v. 129, no. 6, p. 749-758, 2006.

8. GRAY, J. B. et al. Studies on the efficiency of implants as orthodontic anchorage. Am. J. Orthod. Dentofacial Orthop., St. Louis, v. 83, p. 311-317, 1983.

9. GREENBAUM, K. R.; ZACHRISSON, B. U. The effect of palatal expansion therapy on the periodontal supporting tissues. Am. J. Orthod. Dentofacial Orthop., St. Louis, v. 81, no. 1, p. 12-21, Jan. 1982.

10. HAAS, A. Rapid palatal expansion: a recommended prerequisite to Class III treatment. Trans. Eur. Orthod. Soc., London, p. 311 318, 1973.

11. HAAS, A. Long-term posttreatment of rapid palatal expansion. Angle Orthod., Appleton, v. 50, no. 3, p. 189-217, July 1980.

12. HAAS, A. J. Rapid expansion of the maxillary dental arch and nasal cavity by opening the midpalatal suture. Angle Orthod., Appleton, v. 31, no. 2, p. 73-90, Apr. 1961.

13. HARZER, W. et al. Rapid maxillary expansion with palatal anchorage of the hyrax expansion screw-pilot study with case presentation. J. Orofac. Orthop., München v. 65, no. 5, p. 419-424, Sept. 2004.

14. HIGUCHI, K. W.; SLACK, J. M. The use of titanium fixtures for intraoral anchorage to facilitate orthodontic tooth movement. Int. J. Oral Maxillofac. Implants, Lombard, v. 6, no. 3, p. 3344-3384, Fall 1991.

15. KREBS, A. Midpalatal suture expansion studies by the implant method over a seven-year period. Rep. Congr. Eur. Orthod. Soc., London, v. 40, p. 131-142, 1964.
16. ODENRICK, L. et al. Surface resorption following two forms of rapid maxillary expansion. Eur. J. Orthod., Oxford, v. 13, no. 4, p. 264-270, Aug. 1991.

17. PARR, J. A. et al. Sutural expansion using rigidly integrated osseous implants: an experimental study in rabitts. Angle Orthod. Appleton, v. 67, no. 4, p. 283-290, 1997

18. ROBERTS, W. et al. Osseous adaptation to continuous loading of rigid endosseous implants. Am. J. Orthod. Dentofacial Orthop. St. Louis, v. 86, no. 2, p. 95-111, Aug. 1984.

19. SÄRNAS, K. V. et al. Long-term effect of rapid maxillary expansion studied in one patient with the aid of metallic implants and roentgen stereometry. Eur. J. Orthod., Oxford, v. 14, no. 6, p. 427-432, Dec. 1992.

20. SMALLEY, W. M. et al. Osseointegrated titanium implants for maxillofacial protraction in monkeys. Am. J. Orthod. Dentofacial Orthop., St. Louis, v. 94, no. 4, p. 285-295, Oct. 1988.

21. TIMMS, D. J. An occlusal analysis of lateral maxillary expansion with midpalatal suture opening. Dent. Pract. Dent. Rec., Bristol, v. 18 , no. 12, p. 435-440, Aug. 1968.

22. TURLEY, P. K. The loading of bioglass-coated aluminium oxide implants to produce sutural expansion of the maxillary complex in the pigtail monkey (Macaca menestrina). Arch. Oral Biol., Oxford, v. 25, p. $459-464.1980$.

23. TURLEY, P. K. et al. Orthodontic force application to titanium endosseous implants. Angle Orthod., Appleton, v. 58, no. 2, p. 151-162, Apr. 1988.

24. VANARSDALL JR., R. L. Periodontal/Orthodontic interrelationships. In: _. GRABER, T.; VANARSDAL, L R. Orthodontics: current principles and techniques. St. Louis: Mosby, 1994. cap.13, p. 712-749.

25. VANROEKEL, N. B. The use of Branemark system implants for orthodontic anchorage: report of a case. Int. J. Oral Maxillofac. Implants, Lombard, v. 4, p. 341-344, 1989.

26. VARDIMON, A. D. et al. Stability of magnetic versus mechanical palatal expansions. Eur. J. Orthod., Oxford, v. 11, no. 2, p. $107-$ 115, May 1989

27. WERTZ, R. Midpalatal suture opening: a normative study. Am. J. Orthod. Dentofacial Orthop., St. Louis, v. 71, no. 4, p. 367-381, Apr. 1977.

28. WERTZ, R. A. Skeletal and dental changes accompanying rigid midpalatal suture opening. Am. J. Orthod. Dentofacial Orthop., St. Louis, v. 58, no. 1, p. 41-66, July 1970.

\section{Endereço de correspondência}

Daniela G. Garib

Rua Rio Branco n. 19-18

CEP:17.040-480 Bauru / SP

E-mail: dgarib@uol.com.br 